\title{
Sulfurous Gases As Biological Messengers and Toxins: Comparative Genetics of Their Metabolism in Model Organisms
}

\author{
Neal D. Mathew, ${ }^{1}$ David I. Schlipalius, ${ }^{1,2}$ and Paul R. Ebert ${ }^{1}$ \\ ${ }^{1}$ School of Biological Sciences, University of Queensland, St. Lucia Campus, Brisbane, QLD 4072, Australia \\ ${ }^{2}$ Agri-Science Queensland, Department of Employment Economic Development and Innovation, EcoSciences Precinct, \\ GPO Box 46, Brisbane, QLD 4001, Australia
}

Correspondence should be addressed to Paul R. Ebert, p.ebert@uq.edu.au

Received 21 July 2011; Accepted 11 August 2011

Academic Editor: William Valentine

Copyright (C) 2011 Neal D. Mathew et al. This is an open access article distributed under the Creative Commons Attribution License, which permits unrestricted use, distribution, and reproduction in any medium, provided the original work is properly cited.

Gasotransmitters are biologically produced gaseous signalling molecules. As gases with potent biological activities, they are toxic as air pollutants, and the sulfurous compounds are used as fumigants. Most investigations focus on medical aspects of gasotransmitter biology rather than toxicity toward invertebrate pests of agriculture. In fact, the pathways for the metabolism of sulfur containing gases in lower organisms have not yet been described. To address this deficit, we use protein sequences from Homo sapiens to query Genbank for homologous proteins in Caenorhabditis elegans, Drosophila melanogaster, and Saccharomyces cerevisiae. In C. elegans, we find genes for all mammalian pathways for synthesis and catabolism of the three sulfur containing gasotransmitters, $\mathrm{H}_{2} \mathrm{~S}, \mathrm{SO}_{2}$ and COS. The genes for $\mathrm{H}_{2} \mathrm{~S}$ synthesis have actually increased in number in C. elegans. Interestingly, D. melanogaster and Arthropoda in general, lack a gene for 3-mercaptopyruvate sulfurtransferase, an enzym for $\mathrm{H}_{2} \mathrm{~S}$ synthesis under reducing conditions.

\section{Introduction}

Despite initially being thought of only as toxic gases, hydrogen sulfide $\left(\mathrm{H}_{2} \mathrm{~S}\right)$, nitric oxide $(\mathrm{NO})$, and carbon monoxide (CO) are now recognized as important endogenously produced signalling molecules known as gasotransmitters. Wang describes gasotransmitters as small gas molecules that are membrane permeable, endogenously generated, and which have functions at physiologically relevant concentrations [1]. The first two gasotransmitters to be discovered were NO [2] and $\mathrm{CO}[3] . \mathrm{H}_{2} \mathrm{~S}$ was the third identified gasotransmitter $[1,4-7]$. Like $\mathrm{NO}$ and $\mathrm{CO}, \mathrm{H}_{2} \mathrm{~S}$ is also a toxic air pollutant [8-10]. Sulfur dioxide $\left(\mathrm{SO}_{2}\right)$ and carbonyl sulfide (COS) are gaseous toxins that only recently have been shown to be endogenously produced and to transmit biological signals [11]. In this paper, we will discuss the biology of the sulfur containing gasotransmitters and refer to their use as toxins. Our primary objective is to relate what is known in mammals to an understanding of the action of these compounds on invertebrate pests of agriculture. As such, we have augmented the paper with comparative bioinformatics of genes involved in the synthesis and catabolism of $\mathrm{H}_{2} \mathrm{~S}, \mathrm{SO}_{2}$ and COS. This will facilitate future detailed genetic studies into the mode of action of these gasotransmitters/sulphurous fumigants

The strongest evidence that $\mathrm{SO}_{2}$ and $\mathrm{COS}$ are gasotransmitters comes from their effect on smooth muscle cells. Dilation of vascular smooth muscle is caused by the endothelial release of vasodilator substances referred to as endothelium derived relaxing factor (EDRF) [2]. NO is a major mediator of EDRF-induced vasodilation [12], and $\mathrm{H}_{2} \mathrm{~S}$ has been suggested as a secondary EDRF component [13]. However, EDRF causes hyperpolarization in smooth muscle cells, but neither $\mathrm{NO}$ nor $\mathrm{H}_{2} \mathrm{~S}$ cause this effect. It has been suggested that EDRF contains more than one component that causes hyperpolarization, designated endothelium derived hyperpolarizing factors (EDHFs) $[14,15]$. Both $\mathrm{SO}_{2}$ and COS are produced by the porcine coronary artery (PCA), and both have short half-lives of 1-2 seconds, similar to EDHF $[11,16,17]$. Therefore, $\mathrm{SO}_{2}$ and $\mathrm{COS}$ are potential candidates for EDHF [18]. 
TABLE 1: Effects of $\mathrm{H}_{2} \mathrm{~S}$.

\begin{tabular}{ll}
\hline Cause & Effect \\
\hline Vasodilator & $\begin{array}{l}\left.\mathrm{H}_{2} \mathrm{~S} \text { like NO and CO, causes the opening the potassium adenosine triphosphate (K } \mathrm{K}_{\mathrm{ATP}}\right) \\
\text { channels [37] }\end{array}$ \\
Apoptosis modulator & Via the activation of the mitogen-activated protein kinases (MAPK) pathway [41] \\
Protection against oxidative stress & $\begin{array}{l}\text { Increases GSH synthesis and recovery of cysteine transport [24, 42, 43]. Scavenging of } \\
\text { hydroxyl, oxygen and nitric oxide free radicals and reduces the accumulation of lipid } \\
\text { peroxidation [44-46] } \\
\text { Enhances activity of } N \text {-Methyl-D-aspartic acid (NMDA) receptor and activates calcium } \\
\text { channels, which regulates synaptic transmission in neurons [4] }\end{array}$ \\
\hline
\end{tabular}

Sulfur occupies a unique position in biology due to its ability to transfer electrons to and from substrates. Sulfur is a redox chameleon, with approximately ten different states of oxidation [19]. These range from negative two in thiols (RSH) to plus six in sulfate anions $\left(\mathrm{SO}_{4}{ }^{2-}\right)$ and include fractional oxidation states such as -0.5 , found in the disulphide radical anion $\left(\mathrm{RSSR}^{-}\right)$[20]. This unique chemistry allows sulfur to participate in an extensive range of redox events [21]. It also influences the catalytic and metal binding characteristics of the element [22] as well as the activity of the sulfurous gasotransmitters. For example, exposure to sulfur containing gases has a profound effect on cellular metabolic and redox systems [23-25].

We will discuss each of $\mathrm{H}_{2} \mathrm{~S}, \mathrm{SO}_{2}$, and $\mathrm{COS}$, including their chemical properties, their metabolism, and their transport. We will also identify the orthologous sulfur metabolism and transport genes in the genetically tractable model organism Caenorhabditis elegans (C. elegans) as well as Drosophila melanogaster (D. melanogaster) and Saccharomyces cerevisiae (S. cerevisiae). C. elegans orthologues of mammalian genes involved in sulfation have recently been reviewed and will not be discussed here [26].

We propose that fumigants are effective poisons specifically, because they are able to disrupt endogenous gaseous signalling. This hypothesis has a close corollary-that fumigants or their close derivatives may have medically useful effects as modifiers of gasotransmitters at sublethal doses. This paper will facilitate future genetic investigation of these hypotheses.

\section{Hydrogen Sulfide}

$\mathrm{H}_{2} \mathrm{~S}$ is a colourless, odorous, flammable, and water-soluble gas [27]. It is also highly toxic as evidenced by its use in the First World War as a chemical warfare agent [28]. $\mathrm{H}_{2} \mathrm{~S}$ is also a significant air pollutant, particularly in sewerage treatment plants, where it can accumulate to dangerous levels [10]. The toxicity of these gases was initially presumed to be caused by the reversible inhibition of cytochrome c oxidase (COX), the terminal electron acceptor of the electron transport chain (ETC) [29].

It is now recognized that $\mathrm{H}_{2} \mathrm{~S}$ has widespread biological roles. Thus, while $\mathrm{H}_{2} \mathrm{~S}$ does inhibit COX at high concentrations of approximately $80 \mathrm{ppm}$ similar to cyanide, at low concentrations $\mathrm{H}_{2} \mathrm{~S}$ actually stimulates oxygen consumption [30]. $\mathrm{H}_{2} \mathrm{~S}$ is found to efficiently compete with other electron donors. When $\mathrm{H}_{2} \mathrm{~S}$ concentration is high in colonocytes, complex I of the ETC operates in reverse mode and accepts electrons from quinone in order to reduce NAD to NADH [31]. Inhibition of respiration caused by $\mathrm{H}_{2} \mathrm{~S}$ is accompanied by a reversion of the ETC complex II [32].

Exposure to $150 \mathrm{ppm}$ of $\mathrm{H}_{2} \mathrm{~S}$ has been shown to induce a suspended animation like state in mice [33]. C. elegans acclimatized in $50 \mathrm{ppm}$ of $\mathrm{H}_{2} \mathrm{~S}$ results in thermotolerant and an increase in longevity [34]. Resistance to high temperatures in C. elegans often correlates with increased lifespan [35]. The lethal dose, $100 \%$ for C. elegans is $150 \mathrm{ppm}$ of $\mathrm{H}_{2} \mathrm{~S}$. However, acclimatized C. elegans are able to survive being exposed to $500 \mathrm{ppm}[36] . \mathrm{H}_{2} \mathrm{~S}$ also affects the cardiovascular [37], neural [4], digestive, respiratory, endocrine [38], and immune systems at physiological concentrations [39] (Table 1). $\mathrm{H}_{2} \mathrm{~S}$ is endogenously produced during the metabolism of sulfur containing amino acids, in solution $\mathrm{H}_{2} \mathrm{~S}$ dissociates to HS ${ }^{-}$ and $\mathrm{H}^{+}$[40]. These biological activities have led to $\mathrm{H}_{2} \mathrm{~S}$ being acknowledged as the third gasotransmitter following $\mathrm{NO}$ and $\mathrm{CO}[1,4-7]$.

2.1. Synthesis of $\mathrm{H}_{2} \mathrm{~S} . \mathrm{H}_{2} \mathrm{~S}$ is enzymatically generated via the desulfhydration of cysteine by two pyridoxal-phosphate (PLP) dependent enzymes cystathionine- $\beta$-synthase (CBS) [47] and Cystathionine- $\boldsymbol{\gamma}$-lyase (CSE/CTH) [48]. As well as a PLP-independent enzyme 3-mercaptopyruvate sulfurtransferase (3MST/MPST) [49]. Both CBS and CSE are located in the cytosol [50], whereas 3MST is present in the cytosol and the mitochondria [51]. The biosynthetic pathway of $\mathrm{H}_{2} \mathrm{~S}$ is dependent on the tissue location. CBS is the primary source in the brain [52] whereas CSE is the primary source of $\mathrm{H}_{2} \mathrm{~S}$ in blood vessels [41]. Disruption of CSE results in an elevation of blood pressure [53].

Both CBS and CSE affect not only the levels of $\mathrm{H}_{2} \mathrm{~S}$, but also the metabolism of sulfur containing amino acids and the redox state of the cell via their effect on the availability of glutathione (GSH). CBS and CSE are each involved in the homocysteine-dependent transsulfuration pathway. CBS catalyzes the first step in the catabolism of homocysteine to cystathionine, whereas CSE catalyzes the synthesis of cystathionine to cysteine (Figure 1(a)) $[54,55]$. 
(a)

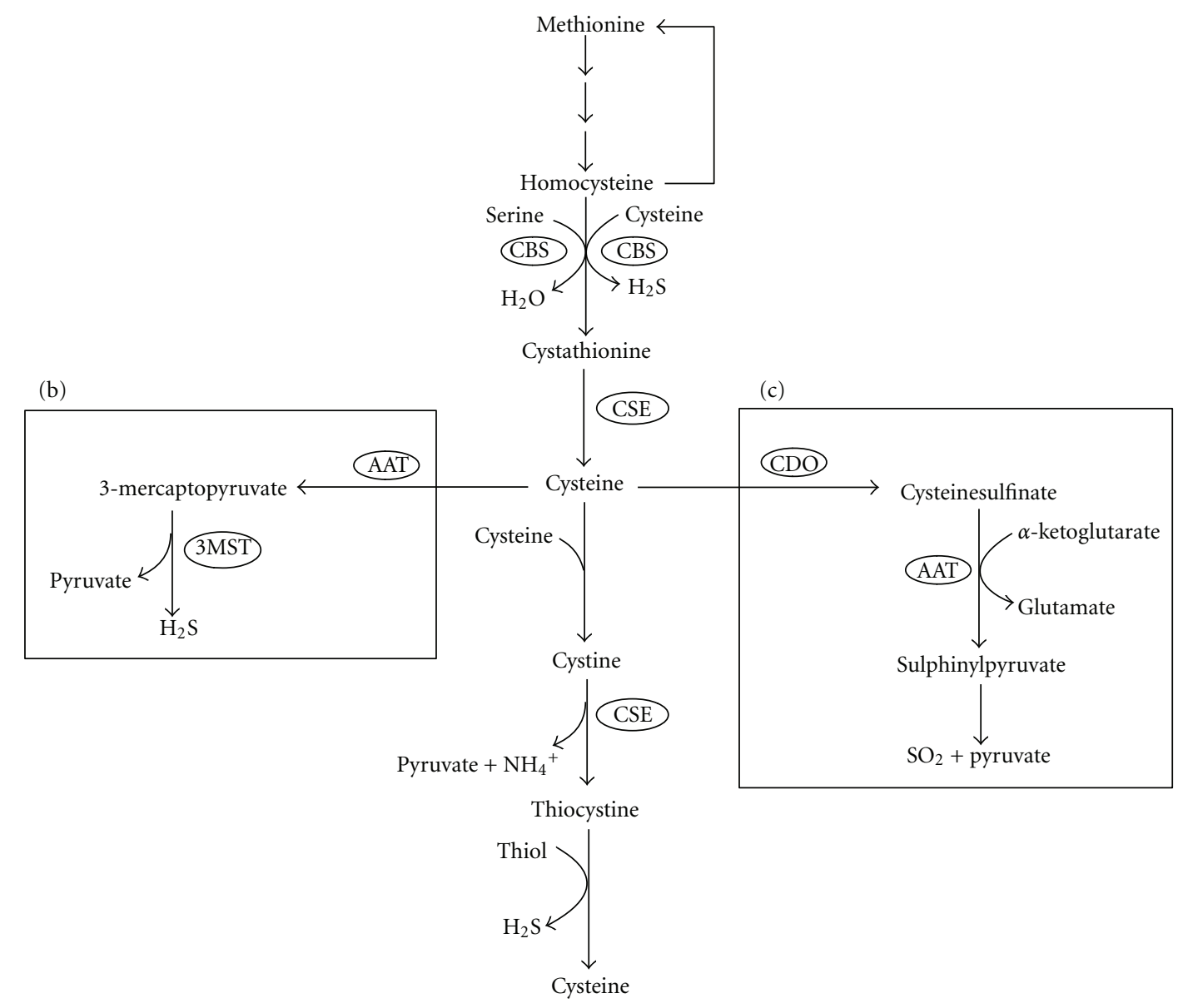

FIGURE 1: Metabolism of sulfur containing amino acids. (a) Homocysteine-dependent transsulfuration pathway that containing both cystathionine- $\beta$-synthase (CBS) and cystathionine- $\gamma$-lyase (CSE). Which is located in the cytosol and generates hydrogen sulfide $\left(\mathrm{H}_{2} \mathrm{~S}\right)$. (b) $\mathrm{H}_{2} \mathrm{~S}$ synthesis via aspartate aminotransferase (AAT) and 3-mercaptopyruvate sulfurtransferase (3MST), which occurs in the cytosol and mitochondria. (c) Catabolism of cysteine via cysteine dioxygenase (CDO) and AAT generates sulfur dioxide $\left(\mathrm{SO}_{2}\right)$.

Availability of the sulfur containing amino acid cysteine is a critical factor in the synthesis of glutathione (GSH) $[56,57]$. Roughly half of the intracellular GSH in the liver is derived from the transsulfuration pathway [58]. GSH and glutathione disulphide (GSSG) are the main thiol/disulphide couple involved in cellular redox maintenance (2GSH/GSSG) $[59,60] . \mathrm{H}_{2} \mathrm{~S}$ increases $\gamma$-Glutamylcysteine, which is a precursor to GSH and causes a recovery of cysteine transport $[42,43]$.

The heme in the CBS enzyme is redox-active and is capable of reversibly regulating the activity of the enzyme according to the redox state. Under reducing conditions cystathionine production is decreased by approximately 1.7 fold [54]. Whereas under oxidising conditions cystathionine production is increased between 1.6 and 2.1 fold [58]. Additionally, the expression of the CSE gene is also induced under oxidising conditions [61]. The redox responsiveness of these two pathways is likely important in order to maintain an appropriate intracellular glutathione pool $[58,62]$.

A third enzyme, 3MST, participates in a two-step pathway of $\mathrm{H}_{2} \mathrm{~S}$ synthesis. Firstly, aspartate aminotransferase
(AAT/ASAT/AspAT/GOT (Glutamic oxaloacetic transaminase)) [63] deaminates cysteine in the presence of $\alpha$ ketoglutarate to generate 3 -mercaptopyruvate and glutamate [64]. Secondly, 3-mercaptopyruvate is desulfhydrated to pyruvate and $\mathrm{H}_{2} \mathrm{~S}$ by $3 \mathrm{MST}$ (Figure 1(b)). However 3MST activity is decreased under oxidative conditions, unlike CBS or CSE [65]. The inhibition results from oxidation of a catalytic cysteine in the active site of $3 \mathrm{MST}$ to sulfenate [66]. This inhibition helps to conserve cysteine in the cell, contributing to the maintenance of cellular redox homeostasis.

2.2. Catabolism of $\mathrm{H}_{2} \mathrm{~S}$. A paralogue of $3 \mathrm{MST}$ called Rhodanese (RHOD) is the principle enzyme involved in the detoxification of $\mathrm{H}_{2} \mathrm{~S}$ in the mitochondria [67]. RHOD is also involved in the detoxification of cyanide [68]. $\mathrm{H}_{2} \mathrm{~S}$ is rapidly oxidized to thiosulfate $\left(\mathrm{S}_{2} \mathrm{O}_{3}{ }^{2-}\right)$ and then converted to sulfite $\left(\mathrm{SO}_{3}{ }^{2-}\right)$ and sulfate $\left(\mathrm{SO}_{4}{ }^{2-}\right)$ [69]. Vertebrate 3MST, which has $59 \%$ homology to RHOD can also potentially detoxify cyanide and $\mathrm{H}_{2} \mathrm{~S}[67,70]$. 


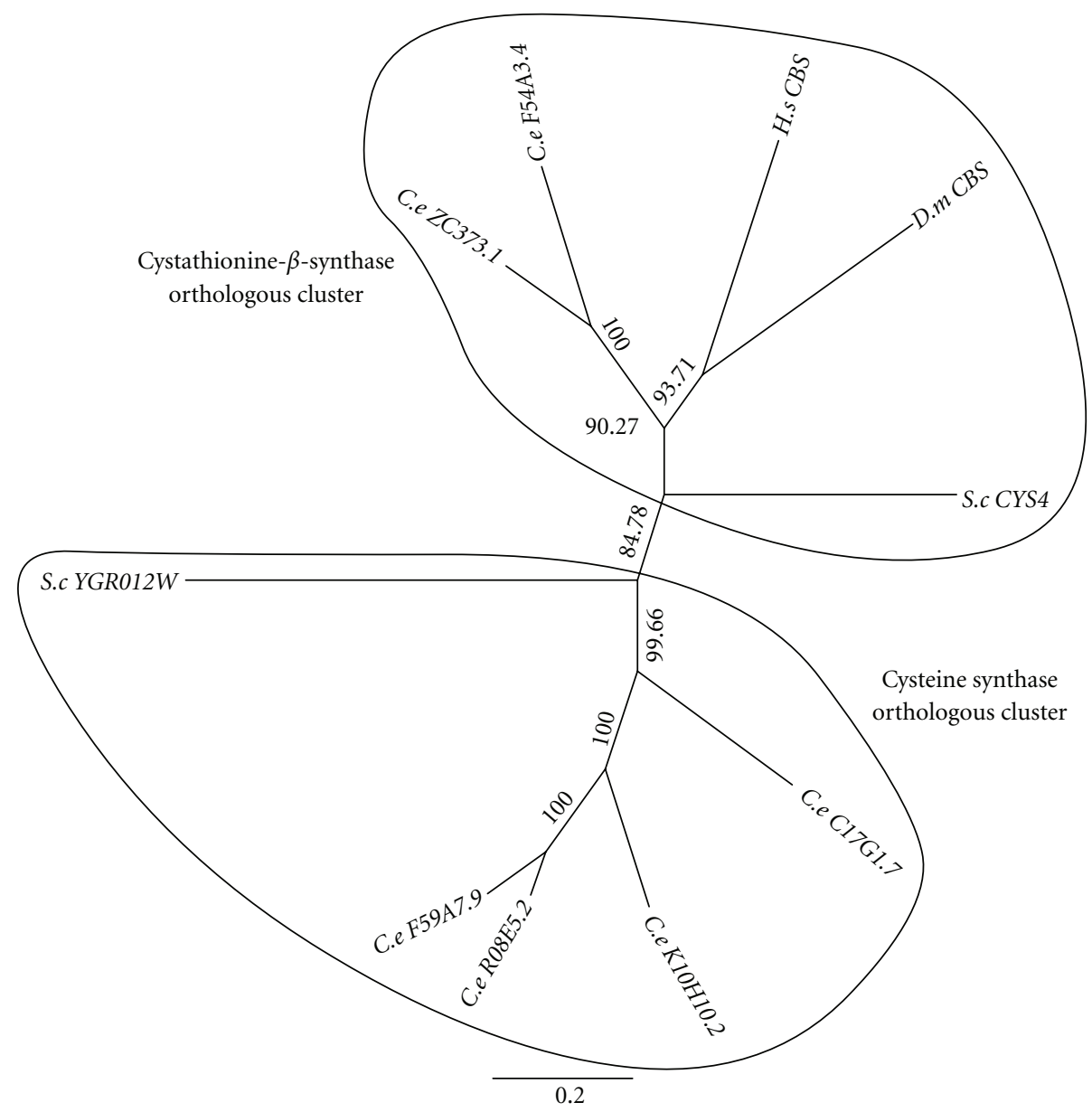

Figure 2: Phylogenetic tree analysis of cystathionine- $\beta$-synthase (CBS) and putative cysteine synthase (PCS). A blast (blastp) search of known Homo sapiens (H.s) proteins was undertaken against three different species, Saccharomyces cerevisiae (S.c), Drosophila melanogaster (D.m), and Caenorhabditis elegans $($ C.e $)$ in the Genbank database. Identified sequences with significant expected value $(\leq 1 \mathrm{E}-10)$ were used to generate a multiple sequence alignment (MSA) via ClustalW 2.1. The MSAs were then trimmed and used to produce an unrooted phylogenetic tree with 10,000 boostraps via Geneious 5.4.

\subsection{C. elegans: Genes Involved in $\mathrm{H}_{2} \mathrm{~S}$ Metabolism and Detoxification}

2.3.1. Cystathionine- $\beta$-Synthase (CBS)/Cysteine Synthase. The S. cerevisiae protein CYS4/YGR155W, C. elegans sequences ZC373.1 and F54A3.4, H. sapiens (CBS), and D. melanogaster (CBS/CG4840) form an orthologous cluster of sequences in the phylogenetic tree (Figure 2). Of these sequences, all but the $C$. elegans sequences have been characterized and shown to be CBS. There is also a somewhat more divergent yeast sequence (YGR012W) that defines a second orthologous cluster containing four $C$. elegans paralogues but no sequences from the other two organisms (Figure 2). YGR012W is a cysteine synthase located on the mitochondrial outer membrane [71].

2.3.2. Cystathionine- $\gamma$-Lyase (CSE). The S. cerevisiae protein CYS3/YAL012W D. melanogaster Eip55E/CG5345, H. sapiens
(CSE), C. elegans sequences CTH-2/ZK1127.10 and CTH$1 / \mathrm{F} 22 \mathrm{~B} 8.6$ form an orthologous cluster of sequences in the phylogenetic tree (Figure 3). S. cerevisiae protein MET17, catalyzes the reaction between $\mathrm{O}$-acetylhomoserine and sulfide, leading to the production of homocysteine $[72,73]$. $S$. cerevisiae proteins STR3 and IRC7 are cystathionine- $\beta$ lyase proteins not found in $H$. sapiens, which are involved in the biosynthesis of methionine $[74,75]$. The $C$. elegans sequence CBL-1/C12C8.2 forms a second orthologous cluster with S. cerevisiae protein IRC7 (Figure 3).

2.3.3. 3-Mercaptopyruvate Sulfurtransferase (3MST) and Rhodanese (RHOD). The S. cerevisiae protein TUM1/YOR251C, $H$. sapiens RHOD and $3 \mathrm{MST}$ as well as seven C. elegans paralogues MPST-1 through MPST-7 form an orthologous cluster of sequences in the phylogenetic tree (Figure 4). It is interesting to note that despite the gene being present in bacteria, yeast, nematodes, and mammals, no orthologous 


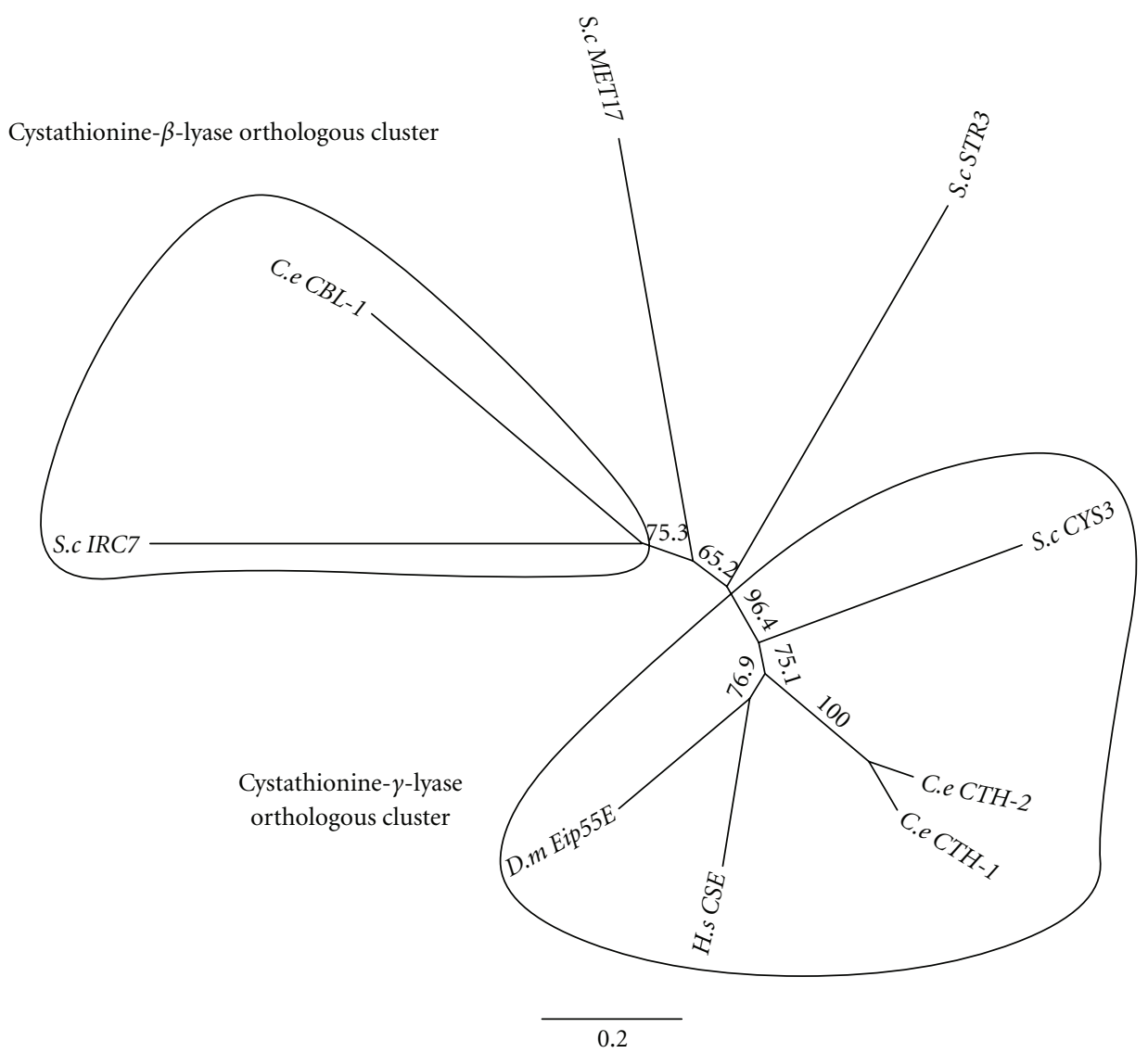

FIGURE 3: Phylogenetic tree analysis of cystathionine- $\gamma$-lyase and Cystathionine- $\beta$-lyase (CBL). F22B8.6 (CTH-1/CSE-1), ZK1127.10 (CTH2/CSE-2), and C12C8.2 (CBL). See Figure 2 for details on the phylogenetic analysis.

sequences exist in the D. melanogaster genome or in any Arthropoda sequences in Genbank.

2.3.4. Aspartate Aminotransferase (AAT). The phylogenetic tree of aspartate aminotransferase sequences splits naturally into two clades. One clade contains the $S$. cerevisiae AAT1/YKL106W and $H$. sapiens AAT-m proteins, both of which are known to be located in the mitochondria. The other clade contains the S. cerevisiae AAT2/YLR027C and H. sapiens AAT-c proteins which are cytoplasmic [76]. The D. melanogaster protein GOT-2/CG4233 and C. elegans GOT- 2.1/C44E4.3 and GOT-2.2/C14F11.1 proteins fall in with the mitochondrial orthologues (Figure 5), which suggests that these proteins are mitochondrial as well. The D. melanogaster protein GOT-1/CG8430 and C. elegans GOT1.1/T01C8.4, GOT-1.2/T01C8.5 and GOT- 1.3/C14E2.2 proteins fall into the cytoplasmic clade (Figure 5), which suggests that these proteins are cytosolic.

\section{Carbonyl Sulfide}

Carbonyl sulfide was first described in 1841 [77]. It is an air pollutant that also has been used as a fumigant [78, 79]. COS is also naturally present in the atmosphere, in water, soil, and plants [80]. COS is biologically generated in bacteria via the enzyme thiocyanate hydrolase, but this enzyme is not present in eukaryotes [81]. Interestingly, COS is detectable in both porcine coronary artery (PCA) and cardiac muscle and is able to induce arterial dilation [18]. As of the writing of this review the eukaryotic pathway of COS biosynthesis is not known. It has been shown, however that stimulation of PCA with acetylcholine causes an increase in synthesis of COS within the coronary artery. This suggests that muscarinic acetylcholine receptors (mAChRs) and not nicotinic acetylcholine receptors (nAChRs) are involved in regulating COS synthesis [18], because mAChRs but not nAChRs are found in the coronary artery [82].

COS is converted via $\alpha$-carbonic anhydrase $(\alpha-\mathrm{CAH})$ to $\mathrm{H}_{2} \mathrm{~S}$ and $\mathrm{CO}_{2}$. In eukaryotes, $\alpha$-CAH is primarily responsible for $\mathrm{pH}$ regulation [83]. The enzyme is widely distributed in mammalian blood and tissue [84]. The toxicity of COS is mediated by $\mathrm{H}_{2} \mathrm{~S}$ as inhibition of $\alpha$-CAH activity decreased the toxicity of COS [85]. It is interesting to note that $\alpha$ $\mathrm{CAH}$ activity can be inhibited via $\mathrm{H}_{2} \mathrm{~S}$ [86]. After exposure to COS, the redox balance of the cell is disrupted and genes that respond to oxidative stress such as glutathione reductase and superoxide dismutase are upregulated [23]. The gene expression effect of exposure to COS is similar to that of phosphine exposure [87]. 


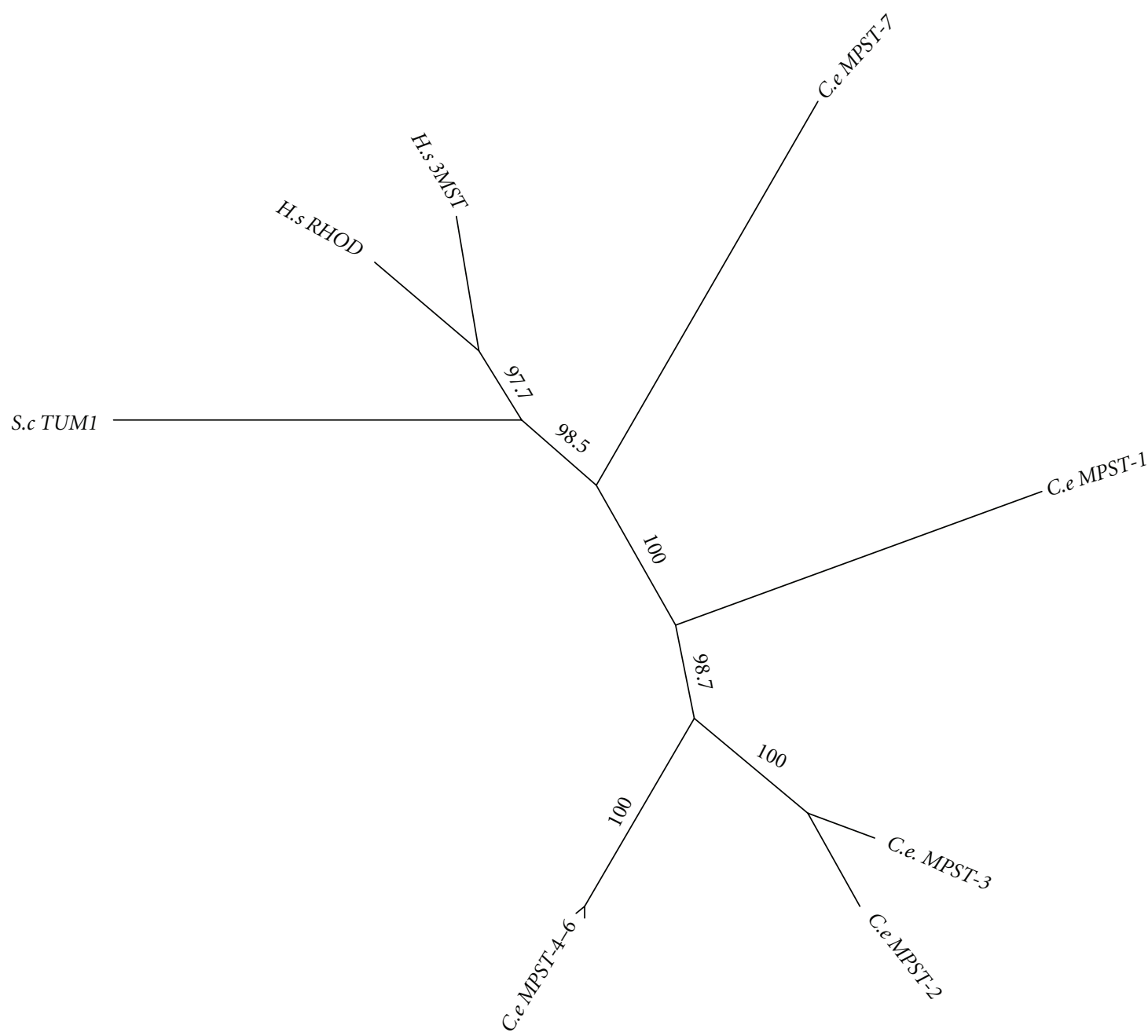

0.3

Figure 4: Phylogenetic tree analysis of 3-mercaptopyruvate sulfurtransferase (3MST/MPST). See Figure 2 for details on the phylogenetic analysis.

3.1. C. elegans: Genes Involved in COS Metabolism and Detoxification. The genes responsible for the synthesis of COS has not yet been identified, but it is known that $\alpha$-carbonic anhydrase $(\alpha-\mathrm{CAH})$ is responsible for the conversion of COS to carbon dioxide and hydrogen sulfide. The C. elegans $\alpha$ carbonic anhydrase gene family has been studied previously. It has six family members, two of which (CAH-3 and CAH4) have been demonstrated to encode functional $\alpha$-CAH enzymes (Table 2) [88]. Additionally C. elegans, S. cerevisiae, and $D$. melanogaster also contain a $\beta$ class of $\mathrm{CAH}$ which is not found $H$. sapiens $[89,90]$.

\section{Sulfur Dioxide}

Like the gases mentioned previously, $\mathrm{SO}_{2}$ is a toxic air pollutant $[91,92]$. It also has the distinction of being the oldest recorded chemical fumigant, as it was used by ancient Egyptians, Greeks, and Romans [93]. It was also used as a chemical warfare agent in a conflict between the Athenians and the Peloponnesians circa 431 B.C. [94] as well as during the Roman siege of Dura-Europos in 256 C.E. [95]. Sulfite, a dissociation product of $\mathrm{SO}_{2}$, is used as a preservative in beverages and food [96].

$\mathrm{SO}_{2}$ is likely to be a signalling molecule as it is produced endogenously from the metabolism of sulfur containing amino acids [97]. Additionally, $\mathrm{SO}_{2}$ has been found to produce biological effects at physiological concentrations [18], such as vasodilation in isolated rat aortic rings [98] and a decrease in blood pressure of male rats $[99,100]$. For these reasons, $\mathrm{SO}_{2}$ has been suggested to be a gasotransmitter [98] .

$\mathrm{SO}_{2}$ can also dissociate to its derivatives in solution, which may also be biologically active. For example, $\mathrm{SO}_{2}$ 


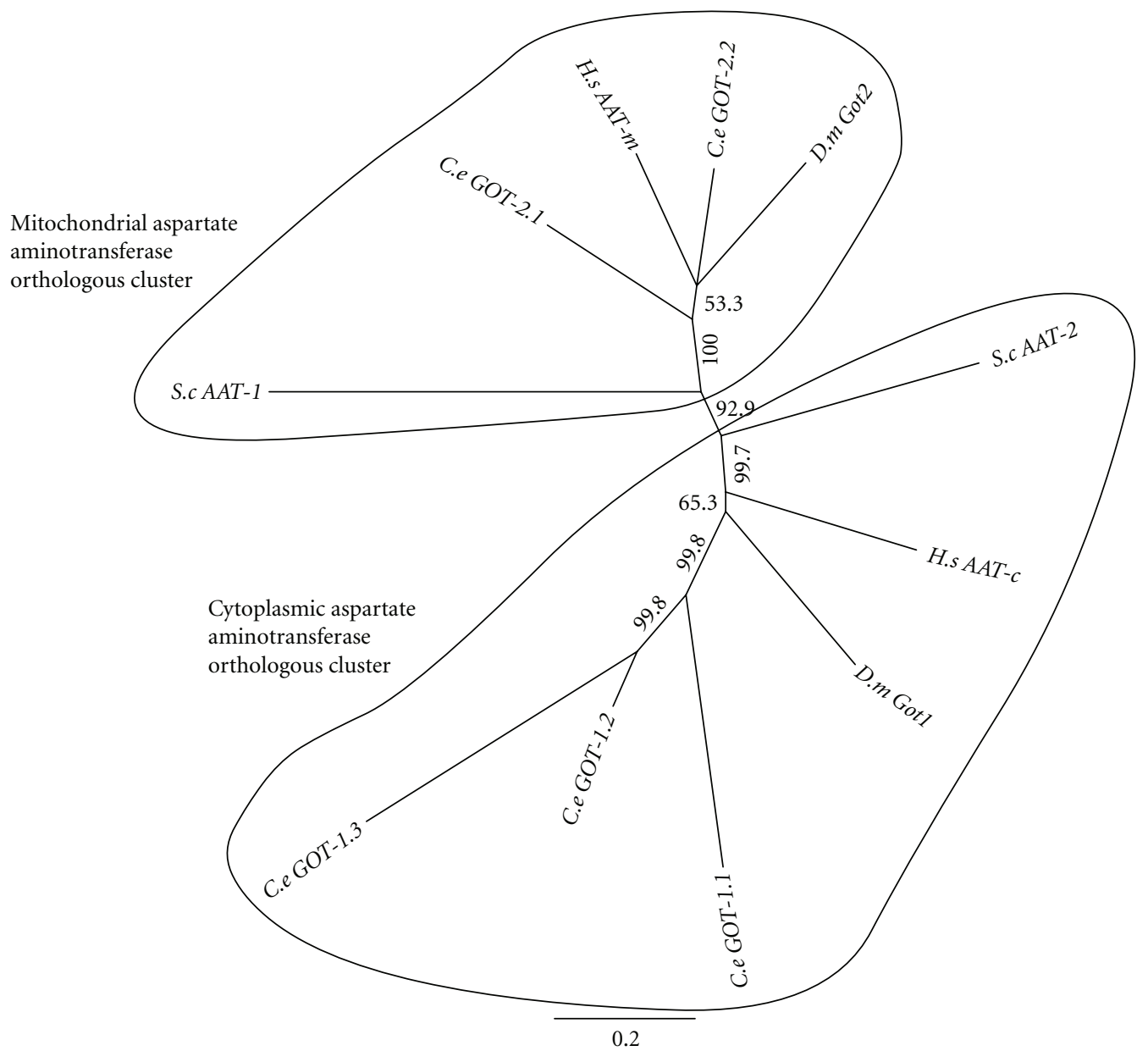

FIGURE 5: Phylogenetic tree analysis of aspartate aminotransferase (AAT/ASAT/AspAT/GOT (glutamic oxaloacetic transaminase)). See Figure 2 for details on the phylogenetic analysis.

TABLe 2: A-CAH C. elegans genes.

\begin{tabular}{lcllr}
\hline Sequence name & Gene name & Predicted/confirmed function & \% Identity & $E$ value \\
\hline F54D8.4 & CAH-1 & $\begin{array}{l}\text { Homo sapiens orthologs_CAH related protein 10 } \\
\text { (partially confirmed via cDNA) }\end{array}$ & $77 / 213(36 \%)$ & $1 e-41$ \\
D1022.8 & CAH-2 & $\begin{array}{l}\text { Homo sapiens orthologs_CAH related protein 10 } \\
\text { (confirmed via cDNA) }\end{array}$ & $106 / 288(37 \%)$ & $7 e-60$ \\
K05G3.3 & CAH-3 & $\begin{array}{l}\text { Homo sapiens } \text { orthologs_CAH7 isoform 1 } \\
\text { (confirmed via cDNA) }\end{array}$ & $96 / 262(37 \%)$ & $2 e-46$ \\
R01E6.3 & CAH-4 & $\begin{array}{l}\text { Homo sapiens orthologs CAH-2 } \\
\text { (confirmed via cDNA) functioning CAH }\end{array}$ & $71 / 234(30 \%)$ & $1 e-30$ \\
R173.1 & CAH-5 & $\begin{array}{l}\text { Homo sapiens orthologs_CAH7 isoform 1 } \\
\text { (confirmed via cDNA) }\end{array}$ & $96 / 261(37 \%)$ & $3 e-49$ \\
T28F2.3 & CAH-6 & $\begin{array}{l}\text { Homo sapiens } \text { orthologs_CAH7 isoform 1 } \\
\text { (partially confirmed via cDNA) }\end{array}$ & $76 / 246(31 \%)$ & $1 e-36$ \\
\hline
\end{tabular}

dissociates into sulfite $\left(\mathrm{SO}_{3}{ }^{2-}\right)$ and bisulfite $\left(\mathrm{HSO}_{3}{ }^{-}\right)$in a $3: 1$ ratio in a neutral solution [101]. Furthermore, both $\mathrm{SO}_{3}{ }^{2-}$ and $\mathrm{HSO}_{3}{ }^{-}$can be oxidized to $\mathrm{SO}_{4}{ }^{2-}$ via sulfite oxidase (SOX) [102]. Vasodilation via $\mathrm{SO}_{2}$, however, has been found to be much greater than dilation induced by $\mathrm{SO}_{2}$ derivatives [103]. It is, therefore, unlikely that activity attributed to $\mathrm{SO}_{2}$ is actually due to the action of derivative compounds.

4.1. Generation of $\mathrm{SO}_{2} . \mathrm{SO}_{2}$ is generated via two different pathways, one enzymatically and one nonenzymatic. The enzymatic metabolism occurs via catabolism of cysteine [49]. 
TABLE 3: Other C. elegans genes involved in $\mathrm{SO}_{2}$.

\begin{tabular}{|c|c|c|c|c|}
\hline Sequence name & Gene name & Predicted/confirmed function & $\%$ identity & $E$ value \\
\hline H13N06.4 & SUOX-1 & Homo sapiens orthologous (confirmed via cDNA) & $230 / 471(49 \%)$ & $3 e-160$ \\
\hline F56F10.3 & CDO-1 & Homo sapiens orthologous (confirmed via cDNA) & $87 / 176(49 \%)$ & $1 e-67$ \\
\hline
\end{tabular}

Cysteine catabolism to cysteinesulfinate is dependent upon cysteine dioxygenase (CDO) [97, 104]. CDO concentration is regulated by the availability of methionine and cysteine or protein [105]. Therefore, CDO is one of the enzymes that regulates free cysteine levels [106]. The key enzyme in the generation of $\mathrm{SO}_{2}$ is AAT, which is constantly being expressed (Figure 1(c)) [107]. However, expression of AAT is increased via glucocorticoids [11, 108]. AAT is expressed in cytosol and mitochondria [109]. Nonenzymatic generation of $\mathrm{SO}_{2}$ occurs at neutrophils as a result of oxidative stress, which causes the conversion of $\mathrm{H}_{2} \mathrm{~S}$ to sulfite [110].

4.2. Toxicity. There is little information available on the mechanism of $\mathrm{SO}_{2}$ toxicity. It potentially involves oxidative damage caused by free radicals formed during sulfite oxidation [111]. Exposure to $\mathrm{SO}_{2}$ has been found to cause lipid peroxidation as well as increase the levels of enzymes that protect cells against oxidative damage caused by reactive oxygen species, including superoxide dismutase, glutathione peroxidase and catalase [112]. Exposure to $\mathrm{SO}_{2}$ also induces chromosomal aberrations, chromatid exchanges and micronuclei formation, as shown in cultured human blood lymphocytes $[113,114]$. Sulfite oxidase (SOX) is involved in oxidative detoxification of sulfite [102, 115]. Deficiency of SOX has previously been demonstrated to increase $\mathrm{SO}_{2}, \mathrm{SO}_{3}{ }^{2-}$, and $\mathrm{HSO}_{3}{ }^{-}$toxicity $[116,117]$. SOX activity has been shown to be significantly different in different mammalian tissues [118]. It is expected the oxidative damage caused by exposure to $\mathrm{SO}_{2}$ would be tissue specific. However it is found that exposure of $\mathrm{SO}_{2}$ caused nearly equal oxidative damage, suggesting that $\mathrm{SO}_{2}$ toxicity is systemic [119].

4.3. C. elegans: Genes Involved in $\mathrm{SO}_{2}$ Metabolism and Detoxification. Phylogenetic analysis was not carried out on the other proteins involved in the synthesis or breakdown of $\mathrm{SO}_{2}$ as no gene duplication had occurred, resulting in a simple one-to-one correspondence between nematode and human sequences. The human gene for cysteine dioxygenase (cdo-1) carries out the initial step in sulfur dioxide synthesis from cysteine. C. elegans has a single counterpart which is also called cdo-1 (Table 3). The second step in sulfur dioxide synthesis is aspartate amino transferase, which is also used elsewhere in sulfur metabolism and is the subject of Figure 5. The final step in the synthesis of sulfur dioxide is the nonenzymatic decomposition of sulfinyl-pyruvate to sulfur dioxide and pyruvate. The oxidation of sulfur dioxide is carried out by SOX-1 in humans, the orthologous C. elegans gene is H13N06.4 (Table 3).

\section{Cross-Talk between Gasotransmitters}

$\mathrm{H}_{2} \mathrm{~S}$ and $\mathrm{SO}_{2}$ have been found to act synergistically with $\mathrm{NO}$ to enhance the vasorelaxant effect $[100,120]$. The vasorelaxant effect of $\mathrm{H}_{2} \mathrm{~S}$ in rat aortic rings can be decreased by removal of the endothelium, interruption of NO synthase or blocking of $\mathrm{Ca}^{2+}$-dependent $\mathrm{K}^{+}$channels [121]. This suggests that $\mathrm{NO}$ and potentially EDHF contribute to the vasorelaxant effect of $\mathrm{H}_{2} \mathrm{~S}$. However, others have not observed synergistic vasorelaxation when $\mathrm{H}_{2} \mathrm{~S}$ and $\mathrm{NO}$ treatments are combined but instead see a decrease in vasorelaxation [122]. This is likely due to reaction between $\mathrm{H}_{2} \mathrm{~S}$ and $\mathrm{NO}$ to generate a nitrosothiol [123].

Synthesis of $\mathrm{H}_{2} \mathrm{~S}$ is increased when exposed to $\mathrm{NO}$ due to the activation of the cyclic guanosine monophosphate pathway, which potentially increases the activity CSE [124]. NO also increases the expression of CSE which is involved in $\mathrm{H}_{2} \mathrm{~S}$ synthesis [37]. It has also been found that metabolism of CO is also enhanced when exposed to $\mathrm{H}_{2} \mathrm{~S}$ [125]. Additionally, $\mathrm{NO}$ and $\mathrm{H}_{2} \mathrm{~S}$ can result in an increase in cysteine uptake $[42,126]$. This increase in cystine uptake can then enhance the synthesis of $\mathrm{H}_{2} \mathrm{~S}$ [127]. In contrast, $\mathrm{H}_{2} \mathrm{~S}$ has been found to suppress $\mathrm{NO}$ synthesis in rats by down regulating the aortic $\mathrm{L}$-arginine-dependent $\mathrm{NO}$ pathway [128]. Exposure to $\mathrm{SO}_{2}$ is found to increase NO pathway [129]. Despite the poor understanding of the cross-talk between gasotransmitters, it is clear that their functions are tightly integrated.

\section{Storage, Release, and Transport}

After the sulfur containing gases are endogenously produced, they can either be immediately released or stored for later release in response to a physiological signal. Unlike the short half-lives of COS and $\mathrm{SO}_{2}$, the half-life of $\mathrm{H}_{2} \mathrm{~S}$ in mammalian plasma is about 30 minutes [130]. Sulfur from the sulfur containing gases can be stored in two forms, acid-labile sulfur or bound sulfane-sulfur. Exogenously $\mathrm{H}_{2} \mathrm{~S}$ is absorbed and stored as bound sulfane-sulfur [131]. Sulfur is released from bound sulfane-sulfur by reduced glutathione and cysteine, or at $\mathrm{pH}$ higher than $8.4[131,132]$. Acid-labile sulfur is generally found as iron-sulfur enzymes in the mitochondria. Sulfur is released from acid-labile sulfur at a $\mathrm{pH}$ of $<5.4$, with little or no $\mathrm{H}_{2} \mathrm{~S}$ released at $\mathrm{pH} \leq 6$ [131].

Bound sulfane-sulfur is generally located in the cytoplasm though there is also evidence of long distance transport [131, 133]. One mechanism of transport has been determined in Lucina pectinata in which the heme group of hemoglobin I (HbI) binds and transports sulfide [97, 134]. In the $\mathrm{C} 1 \mathrm{Hb}$ from Riftia pachyptila, the sulfide is bound to zinc ions [135]. Neither HbI nor C1 Hb are found in C. elegans, though other globular proteins exits which could potentially 
bind to sulfide, providing a mechanism for long distance sulfide transport.

$\mathrm{H}_{2} \mathrm{~S}$ COS and $\mathrm{SO}_{2}$ are able to freely diffuse across the hydrophobic cellular membrane without facilitation via membrane channels [136-138]. Furthermore, no evidence of active membrane transport of $\mathrm{H}_{2} \mathrm{~S}$ has been found [137]. This situation is analogous that of ammonia transport, which is also able to freely diffuse across the cellular membrane. Despite this ability, however, three distinct transport systems exist that actively transport ammonia across cell membranes [139].

\section{Future Directions}

The three sulfur containing gases $\mathrm{H}_{2} \mathrm{~S}, \mathrm{SO}_{2}$, and $\mathrm{COS}$ act as gasotransmitters in vertebrates. The primary bioassay that is used to study the three compounds is vasodilation, though metabolic arrest has also been demonstrated in the case of $\mathrm{H}_{2} \mathrm{~S}$ and all three compounds are known to affect the redox state of cells. Though the compounds have barely been studied in invertebrates, $\mathrm{H}_{2} \mathrm{~S}$ has been shown to mediate lifespan extension and heat tolerance in C. elegans [34] as well as desiccation tolerance in D. melanogaster [140]. Exposure of C. elegans to $\mathrm{SO}_{2}$ induces ovoviviparity [141], which is a stress response in C. elegans [142]. The toxicity of the chemicals when administered at concentrations greater than normal endogenous levels likely reflects their role as potent neurological and physiological signalling molecules. The toxicity has been exploited commercially through the use of these compounds as fumigants.

Characterisation of the roles of these molecules in the model organism, C. elegans, will facilitate the genetic analysis of their function and toxicology with benefits to be gained in agriculture and medicine. A first step toward genetic analysis is to determine the extent to which the metabolic pathways exist in the primary eukaryotic genetic model organisms; S. cerevisiae, C. elegans, and D. melanogaster. Our analysis reveals that all of the metabolic genes are present in yeast. Studies in this organism will be of limited value in understanding how the compounds act in a multicellular animal, however. D. melanogaster and indeed all insects are missing one of the metabolic genes altogether, which will limit the studies that can be considered in this species. The model system C. elegans contains all of the mammalian genes involved in the metabolism of the sulfur containing gases. C. elegans has an additional interesting property. Most genes for synthesis of $\mathrm{H}_{2} \mathrm{~S}$ have been duplicated in $C$. elegans even though single genes exist in the other organisms. This situation likely reflects the stereotypic biology of $C$. elegans in which specific genes act in specific cell types to a greater extent than in other organisms. This may provide a research advantage as genetic manipulations may allow gasotransmitter signalling to be disrupted more specifically than in other organisms.

C. elegans is ideal for the genetic investigation of gasotransmitter action and toxicity as the nematodes are cultured on agar medium which facilitates simultaneous exposure to dissolved chemicals and gases. C. elegans reproduces rapidly as a self-fertilizing hermaphrodite which facilitates the creation of mutant strains. There are also well-defined techniques for transformation and genetic manipulation of gene expression. Furthermore, the stereotypic development of C. elegans means the origin of each cell in the adult is known and the physiological role of each cell is reproducible. Because the organisms are transparent, the physiology of individual cells in the living organism also can often be studies microscopically using fluorescent probes.

Genetic analysis can be carried out in the "forward" direction, which refers to the traditional approach of mutagenesis of all genes in the genome followed by a screen for mutant individuals that exhibit a specific effect (e.g., resistance to $\mathrm{H}_{2} \mathrm{~S}$ ). Analysis then reveals the gene that was mutated and how the phenotype is mediated. Genetic analysis can also be carried out in the reverse direction, which refers to the molecular genetic approach of disrupting a characterised gene that ought to affect a process and then analysing the result. An example would be to individually suppress each CSE gene in C. elegans to see which of them result in phenotypes related to $\mathrm{H}_{2} \mathrm{~S}$ synthesis. Genetic analysis can also be combinatorial, an approach that is greatly facilitated in genetic model organisms, which usually have large collections of characterised mutant strains that are distributed to researchers on request. An example of a combinatorial approach would be to determine the effect of $\mathrm{H}_{2} \mathrm{~S}$ depletion on lifespan in strains carrying known longevity mutations. This would indicate whether the effect of $\mathrm{H}_{2} \mathrm{~S}$ on lifespan is related to any previously described lifespan enhancing mutations.

Major issues remain to be investigated regarding the roles of sulfur containing gases in biology, particularly in invertebrates. These include the possibility of unique roles of the gases within specific subcellular compartments, in specific tissues or at specific times during development. Genetic analysis can be used to identify interactions between gaseous signals and other signalling pathways as well as the influence of redox state on the activity of the gases. Understanding the mechanisms of action can also be used to identify novel fumigants or fumigation synergists of commercial importance. Model organism genetics can also be used for the identification and genetic manipulation of physiological parameters of medical significance that are controlled by the sulfur containing gases. Such physiological states include thermotolerance, desiccation tolerance, reversible metabolic arrest, and hypoxic preconditioning. All of these research targets can be addressed effectively and meaningfully in genetic model organisms such as C. elegans.

\section{References}

[1] R. Wang, “Two's company, three's a crowd: can H2S be the third endogenous gaseous transmitter?" FASEB Journal, vol. 16, no. 13, pp. 1792-1798, 2002.

[2] R. F. Furchgott and J. V. Zawadzki, "The obligatory role of endothelial cells in the relaxation of arterial smooth muscle by acetylcholine," Nature, vol. 288, no. 5789, pp. 373-376, 1980.

[3] A. Verma, D. J. Hirsch, C. E. Glatt, G. V. Ronnett, and S. H. Snyder, "Carbon monoxide: a putative neural messenger," Science, vol. 259, no. 5093, pp. 381-384, 1993. 
[4] K. Abe and H. Kimura, "The possible role of hydrogen sulfide as an endogenous neuromodulator," Journal of Neuroscience, vol. 16, no. 3, pp. 1066-1071, 1996.

[5] K. Qu, S. W. Lee, J. S. Bian, C. M. Low, and P. T. H. Wong, "Hydrogen sulfide: neurochemistry and neurobiology," Neurochemistry International, vol. 52, no. 1-2, pp. 155-165, 2008.

[6] K. R. Olson, "Is hydrogen sulfide a circulating "gasotransmitter" in vertebrate blood?" Biochimica et Biophysica Acta, vol. 1787, no. 7, pp. 856-863, 2009.

[7] T. Chang, A. Untereiner, J. Liu, and L. Wu, "Interaction of methylglyoxal and hydrogen sulfide in rat vascular smooth muscle cells," Antioxidants and Redox Signaling, vol. 12, no. 9, pp. 1093-1100, 2010.

[8] L. Li, A. Hsu, and P. K. Moore, "Actions and interactions of nitric oxide, carbon monoxide and hydrogen sulphide in the cardiovascular system and in inflammation-a tale of three gases!," Pharmacology and Therapeutics, vol. 123, no. 3, pp. 386-400, 2009.

[9] D. Gorman, A. Drewry, Y. L. Huang, and C. Sames, "The clinical toxicology of carbon monoxide," Toxicology, vol. 187, no. 1, pp. 25-38, 2003.

[10] L. J. de Kok, W. Bosma, F. M. Maas, and P. J. C. Kuiper, "The effect of short-term H2S fumigation on water-soluble sulphydryl and glutathione levels in spinach," Plant, Cell \& Environment, vol. 8, no. 3, pp. 189-194, 1985.

[11] H. H. Juang, L. C. Costello, and R. B. Franklin, "Androgen modulation of multiple transcription start sites of the mitochondrial aspartate aminotransferase gene in rat prostate," Journal of Biological Chemistry, vol. 270, no. 21, pp. 12629 12634, 1995.

[12] R. M. J. Palmer, A. G. Ferrige, and S. Moncada, "Nitric oxide release accounts for the biological activity of endotheliumderived relaxing factor," Nature, vol. 327, no. 6122, pp. 524 526, 1987.

[13] N. Shibuya, Y. Mikami, Y. Kimura, N. Nagahara, and H. Kimura, "Vascular endothelium expresses 3-mercaptopyruvate sulfurtransferase and produces hydrogen sulfide," Journal of Biochemistry, vol. 146, no. 5, pp. 623-626, 2009.

[14] G. Chen, H. Suzuki, and A. H. Weston, "Acetylcholine releases endothelium-derived hyperpolarizing factor and EDRF from rat blood vessels," British Journal of Pharmacology, vol. 95, no. 4, pp. 1165-1174, 1988.

[15] J. G. de Mey, M. Claeys, and P. M. Vanhoutte, "Endotheliumdependent inhibitory effect of acetylcholine, adenosine triphosphate, thrombin and arachidonic acid in the canine femoral artery," Journal of Pharmacology and Experimental Therapeutics, vol. 222, no. 1, pp. 166-173, 1982.

[16] D. Gebremedhin, D. R. Harder, P. F. Pratt, and W. B. Campbell, "Bioassay of an endothelium-derived hyperpolarizing factor from bovine coronary arteries: role of a cytochrome P450 metabolite," Journal of Vascular Research, vol. 35, no. 4, pp. 274-284, 1998.

[17] G. Chen, Y. Yamamoto, K. Miwa, and H. Suzuki, "Hyperpolarization of arterial smooth muscle induced by endothelial humoral substances," American Journal of Physiology-Heart and Circulatory Physiology, vol. 260, no. 6, part 2, pp. H1888H1892, 1991.

[18] M. Balazy, I. A. Abu-Yousef, D. N. Harpp, and J. Park, "Identification of carbonyl sulfide and sulfur dioxide in porcine coronary artery by gas chromatography/mass spectrometry, possible relevance to EDHF," Biochemical and Biophysical Research Communications, vol. 311, no. 3, pp. 728-734, 2003.
[19] C. Jacob and A. Anwar, "The chemistry behind redox regulation with a focus on sulphur redox systems," Physiologia Plantarum, vol. 133, no. 3, pp. 469-480, 2008.

[20] J. J. Jones, J. Fan, A. B. Nathens et al., "Redox manipulation using the thiol-oxidizing agent diethyl maleate prevents hepatocellular necrosis and apoptosis in a rodent endotoxemia model," Hepatology, vol. 30, no. 3, pp. 714-724, 1999.

[21] C. Jacob, G. I. Giles, N. M. Giles, and H. Sies, "Sulfur and selenium: the role of oxidation state in protein structure and function," Angewandte Chemie-International Edition, vol. 42, no. 39, pp. 4742-4758, 2003.

[22] N. M. Giles, A. B. Watts, G. I. Giles, F. H. Fry, J. A. Littlechild, and C. Jacob, "Metal and redox modulation of cysteine protein function," Chemistry and Biology, vol. 10, no. 8, pp. 677-693, 2003.

[23] T. Liu, L. Li, Y. Wang, G. Zhan, and B. Liu, "Differential expression profiles of Alternaria alternate genes in response to carbonyl sulfide fumigation," Journal of Microbiology, vol. 48, no. 4, pp. 480-485, 2010.

[24] Y. Kimura, Y. I. Goto, and H. Kimura, "Hydrogen sulfide increases glutathione production and suppresses oxidative stress in mitochondria," Antioxidants and Redox Signaling, vol. 12, no. 1, pp. 1-13, 2010.

[25] Z. Meng, "Oxidative damage of sulfur dioxide on various organs of mice: sulfur dioxide is a systemic oxidative damage agent," Inhalation Toxicology, vol. 15, no. 2, pp. 181-195, 2003.

[26] M. Souhei, D. Katsufumi, and N. Kazushu, "Sulfation and related genes in Caenorhabditis elegans," Trends in Glycoscience and Glycotechnology, vol. 21, no. 119, pp. 179-191, 2009.

[27] R. P. Smith and R. E. Gosselin, "Hydrogen sulfide poisoning," Journal of Occupational and Environmental Medicine, vol. 21, no. 2, pp. 93-97, 1979.

[28] M. G. C. H. Foulkes, “Gas!” the Story of the Special Brigade, The Naval \& Military Press, 2001.

[29] R. J. Reiffenstein, W. C. Hulbert, and S. H. Roth, "Toxicology of hydrogen sulfide," Annual Review of Pharmacology and Toxicology, vol. 32, pp. 109-134, 1992.

[30] C. E. Cooper and G. C. Brown, "The inhibition of mitochondrial cytochrome oxidase by the gases carbon monoxide, nitric oxide, hydrogen cyanide and hydrogen sulfide: chemical mechanism and physiological significance," Journal of Bioenergetics and Biomembranes, vol. 40, no. 5, pp. 533-539, 2008.

[31] E. Lagoutte, S. Mimoun, M. Andriamihaja, C. Chaumontet, F. Blachier, and F. Bouillaud, "Oxidation of hydrogen sulfide remains a priority in mammalian cells and causes reverse electron transfer in colonocytes," Biochimica et Biophysica Acta, vol. 1797, no. 8, pp. 1500-1511, 2010.

[32] M. Goubern, M. Andriamihaja, T. Nübel, F. Blachier, and F. Bouillaud, "Sulfide, the first inorganic substrate for human cells," FASEB Journal, vol. 21, no. 8, pp. 1699-1706, 2007.

[33] E. Blackstone, M. Morrison, and M. B. Roth, "H2S induces a suspended animation-like state in mice," Science, vol. 308, no. 5721 , p. 518, 2005.

[34] D. L. Miller and M. B. Roth, "Hydrogen sulfide increases thermotolerance and lifespan in Caenorhabditis elegans," Proceedings of the National Academy of Sciences of the United States of America, vol. 104, no. 51, pp. 20618-20622, 2007.

[35] G. J. Lithgow, T. M. White, S. Melov, and T. E. Johnson, "Thermotolerance and extended life-span conferred by single-gene mutations and induced by thermal stress," 
Proceedings of the National Academy of Sciences of the United States of America, vol. 92, no. 16, pp. 7540-7544, 1995.

[36] M. W. Budde and M. B. Roth, "Hydrogen sulfide increases hypoxia-inducible factor-1 activity independently of von Hippel-Lindau tumor suppressor-1 in C. elegans," Molecular Biology of the Cell, vol. 21, no. 1, pp. 212-217, 2010.

[37] W. Zhao, J. Zhang, Y. Lu, and R. Wang, "The vasorelaxant effect of $\mathrm{H} 2 \mathrm{~S}$ as a novel endogenous gaseous KATP channel opener," EMBO Journal, vol. 20, no. 21, pp. 6008-6016, 2001.

[38] C. D. Russo, G. Tringali, E. Ragazzoni et al., "Evidence that hydrogen sulphide can modulate hypothalamo-pituitaryadrenal axis function: in vitro and in vivo studies in the rat," Journal of Neuroendocrinology, vol. 12, no. 3, pp. 225-233, 2000.

[39] A. Esechie, L. Kiss, G. Olah et al., "Protective effect of hydrogen sulfide in a murine model of acute lung injury induced by combined burn and smoke inhalation," Clinical Science, vol. 115, no. 3, pp. 91-97, 2008.

[40] M. H. Stipanuk, "Sulfur amino acid metabolism: pathways for production and removal of homocysteine and cysteine," Annual Review of Nutrition, vol. 24, pp. 539-577, 2004.

[41] G. Yang, X. Sun, and R. Wang, "Hydrogen sulfide-induced apoptosis of human aorta smooth muscle cells via the activation of mitogen-activated protein kinases and caspase3," FASEB Journal, vol. 18, no. 14, pp. 1782-1784, 2004.

[42] Y. Kimura and H. Kimura, "Hydrogen sulfide protects neurons from oxidative stress," FASEB Journal, vol. 18, no. 10, pp. 1165-1167, 2004.

[43] Y. Kimura, R. Dargusch, D. Schubert, and H. Kimura, "Hydrogen sulfide protects HT22 neuronal cells from oxidative stress," Antioxidants and Redox Signaling, vol. 8, no. 3-4, pp. 661-670, 2006.

[44] B. Geng, L. Chang, C. Pan et al., "Endogenous hydrogen sulfide regulation of myocardial injury induced by isoproterenol," Biochemical and Biophysical Research Communications, vol. 318, no. 3, pp. 756-763, 2004.

[45] M. Whiteman, J. S. Armstrong, S. H. Chu et al., "The novel neuromodulator hydrogen sulfide: an endogenous peroxynitrite "scavenger"?" Journal of Neurochemistry, vol. 90, no. 3, pp. 765-768, 2004.

[46] S. K. Yan, T. Chang, H. Wang, L. Wu, R. Wang, and Q. H. Meng, "Effects of hydrogen sulfide on homocysteine-induced oxidative stress in vascular smooth muscle cells," Biochemical and Biophysical Research Communications, vol. 351, no. 2, pp. 485-491, 2006.

[47] M. Swaroop, K. Bradley, T. Ohura et al., "Rat cystathionine $\beta$ synthase. Gene organization and alternative splicing," Journal of Biological Chemistry, vol. 267, no. 16, pp. 11455-11461, 1992.

[48] P. F. Erickson, I. H. Maxwell, L. J. Su, M. Baumann, and L. M. Glode, "Sequence of cDNA for rat cystathionine $\gamma$-lyase and comparison of deduced amino acid sequence with related Escherichia coli enzymes," Biochemical Journal, vol. 269, no. 2, pp. 335-340, 1990.

[49] M. H. Stipanuk and P. W. Beck, "Characterization of the enzymic capacity for cysteine desulphhydration in liver and kidney of the rat," Biochemical Journal, vol. 206, no. 2, pp. 267-277, 1982.

[50] N. Agrawal and R. Banerjee, "Human polycomb 2 protein is a SUMO E3 ligase and alleviates substrate-induced inhibition of cystathionine $\beta$-synthase sumoylation," PLoS ONE, vol. 3, no. 12, Article ID e4032, 2008.
[51] T. Taniguchi and T. Kimura, "Role of 3 mercaptopyruvate sulfurtransferase in the formation of the iron sulfur chromophore of adrenal ferredoxin," Biochimica et Biophysica Acta, vol. 364, no. 2, pp. 284-295, 1974.

[52] K. Eto, M. Ogasawara, K. Umemura, Y. Nagai, and H. Kimura, "Hydrogen sulfide is produced in response to neuronal excitation," Journal of Neuroscience, vol. 22, no. 9, pp. 3386-3391, 2002.

[53] G. Yang, L. Wu, B. Jiang et al., "H2S as a physiologic vasorelaxant: hypertension in mice with deletion of cystathionine $\gamma$-lyase," Science, vol. 322, no. 5901, pp. 587-590, 2008.

[54] S. Taoka, S. Ohja, X. Shan, W. D. Kruger, and R. Banerjee, "Evidence for heme-mediated redox regulation of human cystathionine $\beta$ - synthase activity," Journal of Biological Chemistry, vol. 273, no. 39, pp. 25179-25184, 1998.

[55] L. Diwakar and V. Ravindranath, "Inhibition of cystathionine- $\gamma$-lyase leads to loss of glutathione and aggravation of mitochondrial dysfunction mediated by excitatory amino acid in the CNS," Neurochemistry International, vol. 50, no. 2, pp. 418-426, 2007.

[56] S. Zhang, J. Du, H. Jin et al., "Endogenous sulfur dioxide aggravates myocardial injury in isolated rat heart with ischemia and reperfusion," Transplantation, vol. 87, no. 4, pp. 517-524, 2009.

[57] W. M. Sun, Z. Z. Huang, and S. C. Lu, "Regulation of $\gamma$-glutamylcysteine synthetase by protein phosphorylation," Biochemical Journal, vol. 320, part 1, pp. 321-328, 1996.

[58] E. Mosharov, M. R. Cranford, and R. Banerjee, "The quantitatively important relationship between homocysteine metabolism and glutathione synthesis by the transsulfuration pathway and its regulation by redox changes," Biochemistry, vol. 39, no. 42, pp. 13005-13011, 2000.

[59] D. P. Jones, J. L. Carlson, V. C. Mody, J. Cai, M. J. Lynn, and P. Sternberg, "Redox state of glutathione in human plasma," Free Radical Biology and Medicine, vol. 28, no. 4, pp. 625-635, 2000.

[60] A. Ayer, S. X. Tan, C. M. Grant, A. J. Meyer, I. W. Dawes, and G. G. Perrone, "The critical role of glutathione in maintenance of the mitochondrial genome," Free Radical Biology and Medicine, vol. 49, no. 12, pp. 1956-1968, 2010.

[61] J. A. Martín, J. Pereda, I. Martínez-López et al., "Oxidative stress as a signal to up-regulate gamma-cystathionase in the fetal-to-neonatal transition in rats," Cellular and Molecular Biology, vol. 53, pp. OL1010-OL1017, 2007.

[62] R. Banerjee and C. G. Zou, "Redox regulation and reaction mechanism of human cystathionine- $\beta$ - synthase: a PLPdependent hemesensor protein," Archives of Biochemistry and Biophysics, vol. 433, no. 1, pp. 144-156, 2005.

[63] R. Akagi, "Purification and characterization of cysteine aminotransferase from rat liver cytosol," Acta Medica Okayama, vol. 36, no. 3, pp. 187-197, 1982.

[64] S. M. Kuo, T. C. Lea, and M. H. Stipanuk, "Developmental pattern, tissue distribution, and subcellular distribution of cysteine: $\alpha$-ketoglutarate aminotransferase and 3-merceptopyruvate sulfurtransferase activities in the rat," Biology of the Neonate, vol. 43, no. 1-2, pp. 23-32, 1983.

[65] N. Nagahara and A. Katayama, "Post-translational regulation of mercaptopyruvate sulfurtransferase via a low redox potential cysteine-sulfenate in the maintenance of redox homeostasis," Journal of Biological Chemistry, vol. 280, no. 41, pp. 34569-34576, 2005.

[66] N. Nagahara, T. Yoshii, Y. Abe, and T. Matsumura, "Thioredoxin-dependent enzymatic activation of mercaptopyruvate sulfurtransferase: an intersubunit disulfide bond 
serves as a redox switch for activation," Journal of Biological Chemistry, vol. 282, no. 3, pp. 1561-1569, 2007.

[67] R. Picton, M. C. Eggo, G. A. Merrill, M. J. S. Langman, and S. Singh, "Mucosal protection against sulphide: importance of the enzyme rhodanese," Gut, vol. 50, no. 2, pp. 201-205, 2002.

[68] B. Sorbo, "Sulfite and complex-bound cyanide as sulfur acceptors for rhodanese," Acta Chemica Scandinavica, vol. 11, no. 4, pp. 628-633, 1957.

[69] T. M. Hildebrandt and M. K. Grieshaber, "Three enzymatic activities catalyze the oxidation of sulfide to thiosulfate in mammalian and invertebrate mitochondria," FEBS Journal, vol. 275, no. 13, pp. 3352-3361, 2008.

[70] D. A. Wing and S. I. Baskin, "Modifiers of mercaptopyruvate sulfurtransferase catalyzed conversion of cyanide to thiocyanate in vitro," Journal of Biochemical Toxicology, vol. 7, no. 2, pp. 65-72, 1992.

[71] R. P. Zahedi, A. Sickmann, A. M. Boehm et al., "Proteomic analysis of the yeast mitochondrial outer membrane reveals accumulation of a subclass of preproteins," Molecular Biology of the Cell, vol. 17, no. 3, pp. 1436-1450, 2006.

[72] A. Spiropoulos and L. F. Bisson, "MET17 and hydrogen sulfide formation in Saccharomyces cerevisiae," Applied and Environmental Microbiology, vol. 66, no. 10, pp. 4421-4426, 2000.

[73] A. Hébert, S. Casaregola, and J. M. Beckerich, "Biodiversity in sulfur metabolism in hemiascomycetous yeasts," FEMS Yeast Research, vol. 11, no. 4, pp. 366-378, 2011.

[74] L. Barreto, A. Garcerá, K. Jansson, P. Sunnerhagen, and E. Herrero, "A peroxisomal glutathione transferase of Saccharomyces cerevisiae is functionally related to sulfur amino acid metabolism," Eukaryotic Cell, vol. 5, no. 10, pp. 1748-1759, 2006.

[75] K. S. Howell, M. Klein, J. H. Swiegers et al., "Genetic determinants of volatile-thiol release by Saccharomyces cerevisiae during wine fermentation," Applied and Environmental Microbiology, vol. 71, no. 9, pp. 5420-5426, 2005.

[76] J. M. Doyle, M. E. Schininà, F. Bossa, and S. Doonan, "The amino acid sequence of cytosolic aspartate aminotransferase from human liver," Biochemical Journal, vol. 270, no. 3, pp. 651-657, 1990.

[77] J. P. Couërbe, "Ueber den Schwefelkohlenstoff," Journal für Praktische Chemie, vol. 23, no. 1, pp. 83-124, 1841.

[78] P. D. N. Svoronost and T. J. Bruno, "Carbonyl sulfide: a review of its chemistry and properties," Industrial and Engineering Chemistry Research, vol. 41, no. 22, pp. 5321-5336, 2002.

[79] V. S. Haritos and G. Dojchinov, "Carbonic anhydrase metabolism is a key factor in the toxicity of $\mathrm{CO}_{2}$ and COS but not $\mathrm{CS}_{2}$ toward the flour beetle Tribolium castaneum [Coleoptera: Tenebrionidae]," Comparative Biochemistry and Physiology C, vol. 140, no. 1, pp. 139-147, 2005.

[80] Y. Ren, "Natural occurrence of carbonyl sulfide and ethyl formate in grains," in Proceedings of the International Conference on Controlled Atmosphere and Fumigation in Stored Products, 2002.

[81] Y. Katayama, Y. Narahara, Y. Inoue, F. Amano, T. Kanagawa, and H. Kuraishi, "A thiocyanate hydrolase of Thiobacillus thioparus. A novel enzyme catalyzing the formation of carbonyl sulfide from thiocyanate," Journal of Biological Chemistry, vol. 267, no. 13, pp. 9170-9175, 1992.

[82] M. P. Caulfield, "Muscarinic receptors-characterization, coupling and function," Pharmacology and Therapeutics, vol. 58, no. 3, pp. 319-379, 1993.
[83] H. C. Blair, "How the osteoclast degrades bone," BioEssays, vol. 20 , no. 10 , pp. $837-846,1998$.

[84] A. R. Bartholomaeus and V. S. Haritos, "Review of the toxicology of carbonyl sulfide, a new grain fumigant," Food and Chemical Toxicology, vol. 43, no. 12, pp. 1687-1701, 2005.

[85] C. P. Chengelis and R. A. Neal, "Studies of carbonyl sulfide toxicity: metabolism by carbonic anhydrase," Toxicology and Applied Pharmacology, vol. 55, no. 1, pp. 198-202, 1980.

[86] A. F. Almeida and T. L. Guidotti, "Differential sensitivity of lung and brain to sulfide exposure: a peripheral mechanism for apnea," Toxicological Sciences, vol. 50, no. 2, pp. 287-293, 1999.

[87] C. H. Hsu, B. C. Chi, M. Y. Liu, J. H. Li, C. J. Chen, and R. Y. Chen, "Phosphine-induced oxidative damage in rats: role of glutathione," Toxicology, vol. 179, no. 1-2, pp. 1-8, 2002.

[88] M. K. Fasseas, D. Tsikou, E. Flemetakis, and P. Katinakis, "Molecular and biochemical analysis of the $\alpha$ class carbonic anhydrases in Caenorhabditis elegans," Molecular Biology Reports, vol. 38, no. 3, pp. 1777-1785, 2011.

[89] M. K. Fasseas, D. Tsikou, E. Flemetakis, and P. Katinakis, "Molecular and biochemical analysis of the $\beta$ class carbonic anhydrases in Caenorhabditis elegans," Molecular Biology Reports, vol. 37, no. 6, pp. 2941-2950, 2010.

[90] L. Syrjänen, M. Tolvanen, M. Hilvo et al., "Characterization of the first beta-class carbonic anhydrase from an arthropod (Drosophila melanogaster) and phylogenetic analysis of betaclass carbonic anhydrases in invertebrates," BMC Biochemistry, vol. 11, no. 1, p. 28, 2010.

[91] S. E. Manahan, Toxicological Chemistry, CRC Press, 1992.

[92] K. Tanaka and K. Sugahara, "Role of superoxide dismutase in defense against SO2 toxicity and an increase in superoxide dismutase activity with SO2 fumigation," Plant and Cell Physiology, vol. 21, no. 4, pp. 601-611, 1980.

[93] R. S. Jackson, Wine Science : Principles and Applications, Elsevier/Academic Press, Boston, Mass, USA, 2008.

[94] Thucydides, History of the Peloponnesian War 431 BC: p. 3.89.2-5.

[95] S. James, "Stratagems, combat, and "chemical warfare" in the siege mines of Dura-Europos," American Journal of Archaeology, vol. 115, no. 1, pp. 69-101, 2011.

[96] A. F. Gunnison, "Sulphite toxicity: a critical review of in vitro and in vivo data," Food and Cosmetics Toxicology, vol. 19, no. 5, pp. 667-682, 1981.

[97] M. H. Stipanuk, J. de la Rosa, and L. L. Hirschberger, "Catabolism of cyst(e)ine by rat renal cortical tubules," Journal of Nutrition, vol. 120, no. 5, pp. 450-458, 1990.

[98] Z. Meng and H. Zhang, "The vasodilator effect and its mechanism of sulfur dioxide-derivatives on isolated aortic rings of rats," Inhalation Toxicology, vol. 19, no. 11, pp. 979986, 2007.

[99] Z. Meng, H. Geng, J. Bai, and G. Yan, "Blood pressure of rats lowered by sulfur dioxide and its derivatives," Inhalation Toxicology, vol. 15, no. 9, pp. 951-959, 2003.

[100] J. Li and Z. Meng, "The role of sulfur dioxide as an endogenous gaseous vasoactive factor in synergy with nitric oxide," Nitric Oxide_Biology and Chemistry, vol. 20, no. 3, pp. 166-174, 2009.

[101] R. Shapiro, "Genetic effects of bisulfite (sulfur dioxide)," Mutation Research, vol. 39, no. 2, pp. 149-175, 1977.

[102] H. J. Cohen, R. T. Drew, J. L. Johnson, and K. V. Rajagopalan, "Molecular basis of the biological function of molybdenum. The relationship between sulfite oxidase and the acute toxicity of bisulfite and SO2," Proceedings of the National 
Academy of Sciences of the United States of America, vol. 70, no. 12, pp. 3655-3659, 1973.

[103] Z. Meng, J. Li, Q. Zhang et al., "Vasodilator effect of gaseous sulfur dioxide and regulation of its level by Ach in rat vascular tissues," Inhalation Toxicology, vol. 21, no. 14, pp. 1223-1228, 2009.

[104] B. McDonagh, S. Ogueta, G. Lasarte, C. A. Padilla, and J. A. Bárcena, "Shotgun redox proteomics identifies specifically modified cysteines in key metabolic enzymes under oxidative stress in Saccharomyces cerevisiae," Journal of Proteomics, vol. 72, no. 4, pp. 677-689, 2009.

[105] D. L. Bella, C. Hahn, and M. H. Stipanuk, "Effects of nonsulfur and sulfur amino acids on the regulation of hepatic enzymes of cysteine metabolism," American Journal of Physiology, vol. 277, no. 1, part 1, pp. E144-E153, 1999.

[106] J. E. Dominy, L. L. Hirschberger, R. M. Coloso, and M. H. Stipanuk, "Regulation of cysteine dioxygenase degradation is mediated by intracellular cysteine levels and the ubiquitin-26 S proteasome system in the living rat," Biochemical Journal, vol. 394, no. 1, pp. 267-273, 2006.

[107] S. X. Du, H. F. Jin, D. F. Bu et al., "Endogenously generated sulfur dioxide and its vasorelaxant effect in rats," Acta Pharmacologica Sinica, vol. 29, no. 8, pp. 923-930, 2008.

[108] M. Aggerbeck, M. Garlatti, S. Feilleux-Duché et al., "Regulation of the cytosolic aspartate aminotransferase housekeeping gene promoter by glucocorticoids, cAMP, and insulin," Biochemistry, vol. 32, no. 35, pp. 9065-9072, 1993.

[109] T. Tsuzuki, K. Obaru, C. Setoyama, and K. Shimada, "Structural organization of the mouse mitochondrial aspartate aminotransferase gene," Journal of Molecular Biology, vol. 198, no. 1, pp. 21-31, 1987.

[110] H. Mitsuhashi, S. Yamashita, H. Ikeuchi et al., "Oxidative stress-dependent conversion of hydrogen sulfide to sulfite by activated neutrophils," Shock, vol. 24, no. 6, pp. 529-534, 2005.

[111] X. Shi, "Generation of SO3/- and $\mathrm{OH}$ radicals in SO3/2reactions with inorganic environmental pollutants and its implications to SO3/2- toxicity," Journal of Inorganic Biochemistry, vol. 56, no. 3, pp. 155-165, 1994.

[112] P. Yargicoglu, E. Şahin, S. Gümüşlü, and A. Ağar, “The effect of sulfur dioxide inhalation on active avoidance learning, antioxidant status and lipid peroxidation during aging," Neurotoxicology and Teratology, vol. 29, no. 2, pp. 211-218, 2007.

[113] Z. Meng and L. Zhang, "Chromosomal aberrations and sister-chromatid exchanges in lymphocytes of workers exposed to sulphur dioxide," Mutation Research, vol. 241, no. 1, pp. 15-20, 1990.

[114] Z. Meng and L. Zhang, "Observation of frequencies of lymphocytes with micronuclei in human peripheral blood cultures from workers in a sulphuric acid factory," Environmental and Molecular Mutagenesis, vol. 15, no. 4, pp. 218220, 1990.

[115] M. Heimberg, I. Fridovich, and P. Handler, "The enzymatic oxidation of sulfite," Journal of Biological Chemistry, vol. 204, no. 2, pp. 913-926, 1953.

[116] E. Calabrese, C. Sacco, G. Moore, and S. DiNardi, "Sulfite oxidase deficiency: a high risk factor in $\mathrm{SO} 2$, sulfite, and bisulfite toxicity?" Medical Hypotheses, vol. 7, no. 2, pp. 133$145,1981$.

[117] A. F. Gunnison, A. Sellakumar, D. Currie, and E. A. Snyder, "Distribution, metabolism and toxicity of inhaled sulfur dioxide and endogenously generated sulfite in the respiratory tract of normal and sulfite oxidase-deficient rats," Journal of
Toxicology and Environmental Health, vol. 21, no. 1-2, pp. 141-162, 1987.

[118] I. Beck-Speier, H. Hinze, and H. Holzer, "Effect of sulfite on the energy metabolism of mammalian tissues in correlation to sulfite oxidase activity," Biochimica et Biophysica Acta, vol. 841, no. 1, pp. 81-89, 1985.

[119] Z. Meng, G. Qin, and B. Zhang, "DNA damage in mice treated with sulfur dioxide by inhalation," Environmental and Molecular Mutagenesis, vol. 46, no. 3, pp. 150-155, 2005.

[120] R. Hosoki, N. Matsuki, and H. Kimura, "The possible role of hydrogen sulfide as an endogenous smooth muscle relaxant in synergy with nitric oxide," Biochemical and Biophysical Research Communications, vol. 237, no. 3, pp. 527-531, 1997.

[121] W. Zhao and R. Wang, "H2S-induced vasorelaxation and underlying cellular and molecular mechanisms," American Journal of Physiology - Heart and Circulatory Physiology, vol. 283, no. 2, pp. H474-H480, 2002.

[122] M. Y. Ali, C. Y. Ping, Y. Y. P. Mok et al., "Regulation of vascular nitric oxide in vitro and in vivo; a new role for endogenous hydrogen sulphide?" British Journal of Pharmacology, vol. 149, no. 6, pp. 625-634, 2006.

[123] M. Whiteman, L. Li, I. Kostetski et al., "Evidence for the formation of a novel nitrosothiol from the gaseous mediators nitric oxide and hydrogen sulphide," Biochemical and Biophysical Research Communications, vol. 343, no. 1, pp. 303-310, 2006.

[124] W. Zhao, J. F. Ndisang, and R. Wang, "Modulation of endogenous production of H2S in rat tissues," Canadian Journal of Physiology and Pharmacology, vol. 81, no. 9, pp. 848-853, 2003.

[125] Z. Qingyou, D. Junbao, Z. Weijin, Y. Hui, T. Chaoshu, and Z. Chunyu, "Impact of hydrogen sulfide on carbon monoxide/heme oxygenase pathway in the pathogenesis of hypoxic pulmonary hypertension," Biochemical and Biophysical Research Communications, vol. 317, no. 1, pp. 30-37, 2004.

[126] H. Li, Z. M. Marshall, and A. R. Whorton, "Stimulation of cystine uptake by nitric oxide: regulation of endothelial cell glutathione levels," American Journal of Physiology, vol. 276, no. 4, part 1, pp. C803-C811, 1999.

[127] D. J. Elsey, R. C. Fowkes, and G. F. Baxter, "L-cysteine stimulates hydrogen sulfide synthesis in myocardium associated with attenuation of ischemia-reperfusion injury," Journal of Cardiovascular Pharmacology and Therapeutics, vol. 15, no. 1, pp. 53-59, 2010.

[128] B. Geng, Y. Cui, J. Zhao et al., "Hydrogen sulfide downregulates the aortic L-arginine/nitric oxide pathway in rats," American Journal of Physiology-Regulatory Integrative and Comparative Physiology, vol. 293, no. 4, pp. R1608-R1618, 2007.

[129] J. Li, R. Li, and Z. Meng, "Sulfur dioxide upregulates the aortic nitric oxide pathway in rats," European Journal of Pharmacology, vol. 645, no. 1-3, pp. 143-150, 2010.

[130] N. L. Whitfield, E. L. Kreimier, F. C. Verdial, N. Skovgaard, and K. R. Olson, "Reappraisal of H2S/sulfide concentration in vertebrate blood and its potential significance in ischemic preconditioning and vascular signaling," American Journal of Physiology-Regulatory Integrative and Comparative Physiology, vol. 294, no. 6, pp. R1930-R1937, 2008.

[131] M. Ishigami, K. Hiraki, K. Umemura, Y. Ogasawara, K. Ishii, and H. Kimura, "A source of hydrogen sulfide and a mechanism of its release in the brain," Antioxidants and Redox Signaling, vol. 11, no. 2, pp. 205-214, 2009. 
[132] J. I. Toohey, "Sulphane sulphur in biological systems: a possible regulatory role," Biochemical Journal, vol. 264, no. 3, pp. 625-632, 1989.

[133] Y. Ogasawara, S. Isoda, and S. Tanabe, "Tissue and subcellular distribution of bound and acid-labile sulfur, and the enzymic capacity for sulfide production in the rat," Biological and Pharmaceutical Bulletin, vol. 17, no. 12, pp. 1535-1542, 1994.

[134] R. Pietri, A. Lewis, R. G. León et al., "Factors controlling the reactivity of hydrogen sulfide with hemeproteins," Biochemistry, vol. 48, no. 22, pp. 4881-4894, 2009.

[135] J. F. Flores, C. R. Fisher, S. L. Carney et al., "Sulfide binding is mediated by zinc ions discovered in the crystal structure of a hydrothermal vent tubeworm hemoglobin," Proceedings of the National Academy of Sciences of the United States of America, vol. 102, no. 8, pp. 2713-2718, 2005.

[136] S. Blezinger, C. Wilhelm, and J. Kesselmeier, "Enzymatic consumption of carbonyl sulfide (COS) by marine algae," Biogeochemistry, vol. 48, no. 2, pp. 185-197, 2000.

[137] J. C. Mathai, A. Missner, P. K. Gler et al., "No facilitator required for membrane transport of hydrogen sulfide," Proceedings of the National Academy of Sciences of the United States of America, vol. 106, no. 39, pp. 16633-16638, 2009.

[138] M. Stratford and A. H. Rose, "Transport of sulphur dioxide by Saccharomyces cerevisiae," Journal of General Microbiology, vol. 132, no. 1, pp. 1-6, 1986.

[139] M. A. Knepper, "NH4+ transport in the kidney," Kidney International, vol. 40, supplement 33, pp. S95-S102, 1991.

[140] J. F. Zhong, S. P. Wang, X. Q. Shi, L. L. Mu, and G. Q. Li, "Hydrogen sulfide exposure increases desiccation tolerance in Drosophila melanogaster," Journal of Insect Physiology, vol. 56, no. 12, pp. 1777-1782, 2010.

[141] J. T. Walker, "Induction of ovoviviparity in Rhabditis by sulfur dioxide," Nematologica, vol. 14, no. 1, p. 148, 1968.

[142] J. Chen and E. P. Caswell-Chen, "Why Caenorhabditis elegans adults sacrifice their bodies to progeny," Nematology, vol. 5, no. 4, pp. 641-645, 2003. 

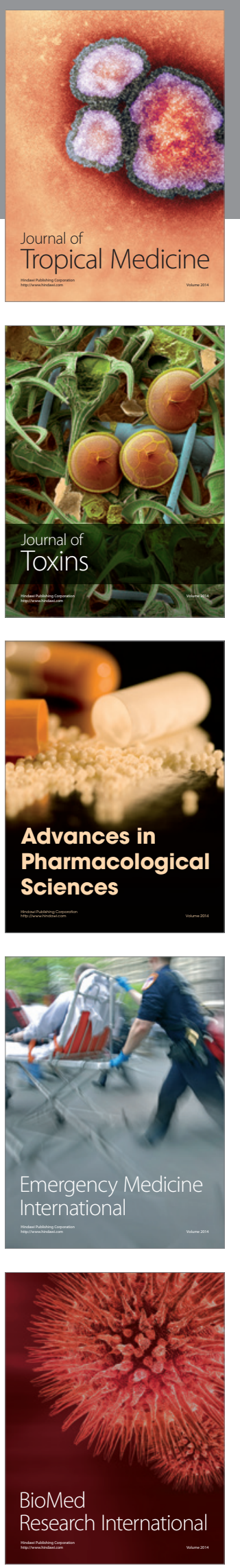
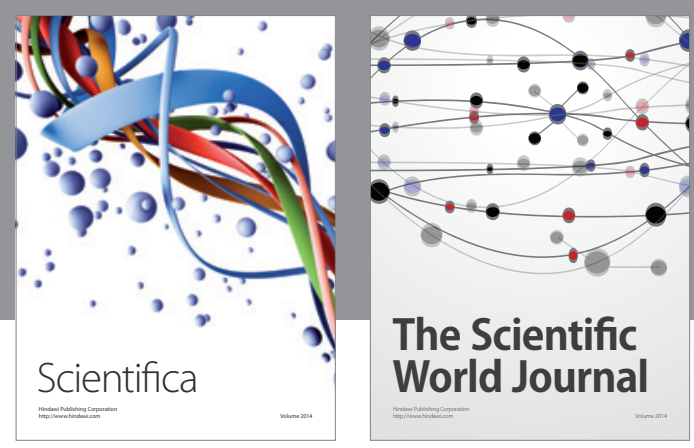

The Scientific World Journal
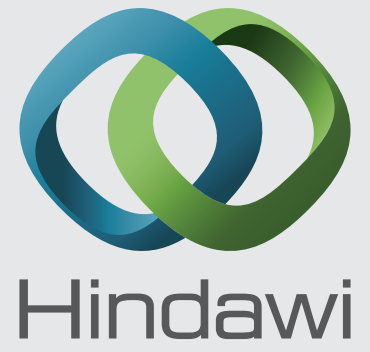

Submit your manuscripts at

http://www.hindawi.com
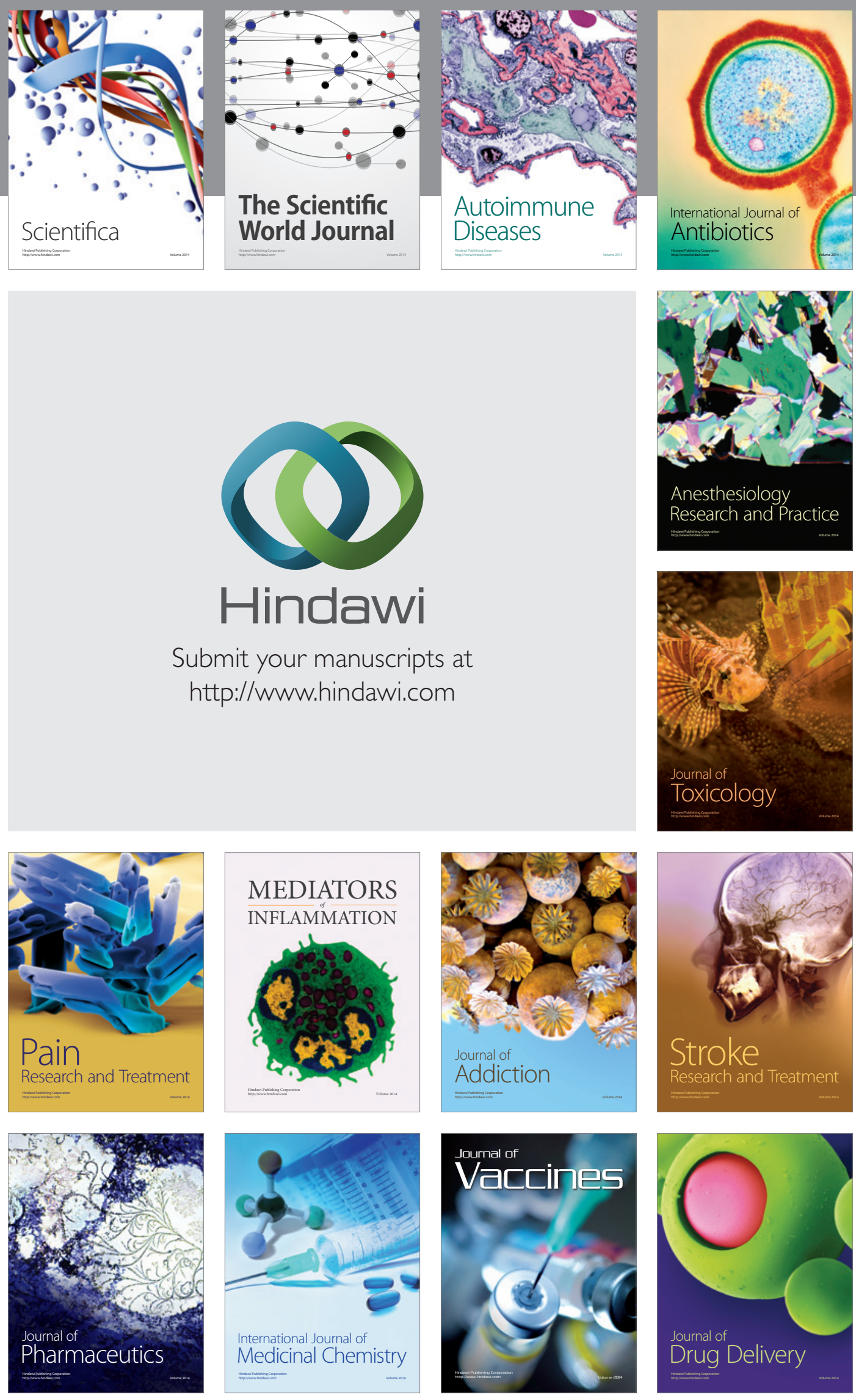